\title{
Anti-loosening performance of coatings on fasteners subjected to dynamic shear load
}

\author{
Junbo ZHOU ${ }^{1}$, Jianhua LIU ${ }^{1}$, Huajiang OUYANG ${ }^{2}$, Zhenbing CAI ${ }^{1}$, Jinfang PENG ${ }^{1}$, Minhao ZHU $^{1, *}$ \\ ${ }^{1}$ Tribology Research Institute, Southwest Jiaotong University, Chengdu 610031, China \\ ${ }^{2}$ School of Engineering, University of Liverpool, Liverpool L69 3GH, UK \\ Received: 02 November 2016 / Revised: 19 March 2017 / Accepted: 24 March 2017 \\ (C) The author(s) 2017. This article is published with open access at Springerlink.com
}

\begin{abstract}
This paper investigates the self-loosening of threaded fasteners subjected to dynamic shear load. Three kinds of typical coatings, PTFE, $\mathrm{MoS}_{2}$, and TiN applied to bolts and nuts, are tested in this investigation. The study experimentally examines the loosening mechanisms of fasteners and assesses the anti-loosening performance of the three tested coatings based on their tightening characteristics, loosening curves, and the damage of thread surface. Additionally, the anti-loosening performance of the three coatings is compared under different load forms. The results indicate that the PTFE and $\mathrm{MoS}_{2}$ coatings have significant anti-loosening effect, whereas the anti-loosening performance of TiN coating is not satisfactory. It is also found that an appropriate increase of the initial tightening torque can significantly improve the anti-loosening effect. In addition, the microscopic analyses of PTFE and $\mathrm{MoS}_{2}$ coating reveal that a reduced initial tightening torque leads to fretting wear on the thread contact surfaces of fasteners, thereby aggravating the damage.
\end{abstract}

Keywords: bolted fastener; loosening curve; fretting, coating; dynamic shear load

\section{Introduction}

The most common modes of threaded fasteners failure under dynamic loads are fatigue and self-loosening. Self-loosening is often encountered when threaded fasteners are subjected to transverse or shear load, which can cause gradual loss or even complete loss of the clamping force in bolted connections. Ultimately, it is likely to lead to the occurrence of severe safety related accidents. There has been much research on this topic. Self-loosening mechanisms [1-16] and their various influencing factors [17-21] were studied through experiments, theoretical analyses and numerical simulation. A variety of measures were proposed to prevent self-loosening, such as chemical locking [21], step lock bolt (SLB) [22], and double-nut [8, 23]. However, loosening of threaded fasteners is still common. Therefore, an in-depth study of threaded fasteners loosening mechanisms is necessary to improve the anti-loosening performance of the bolted connections.

Recently, the loosening process of threaded fasteners had been extensively studied under different loading conditions. However, there has not been a universal acceptance regarding the self-loosening process mechanisms. The focus of the early research in the field was on loosening due to axial loading (dynamic loads acting along the fastener axis) [1-6]. Goodier et al. highlighted the radial sliding motions between the threads of the bolt and the nut or the interfaces of the clamped bearing surfaces as important factors causing loosening of a threaded coupling structure under axial vibration [1]. Basava and Hess found that the clamping force could remain steady, decrease, or increase when the assembly was subjected to axial vibration, which was related to the vibration frequency, amplitude,

* Corresponding author: Minhao ZHU, E-mail: zhuminhao@swjtu.cn 
and the frictional force between the contact surfaces [2]. However, Sakai pointed out that the clamping force might be reduced under the axial vibration [3]. Nassar and co-workers considered the irreversible plastic deformation of bolts under axial vibration as a major loosening mechanism [4, 5]. Additionally, Liu et al. found that the plastic deformation of the structure and fretting wear between contact surfaces were the loosening mechanism of bolted joints under axial excitation [6].

On the other hand, the experimental studies by Junker in 1960s demonstrated that loosening was more severe when a joint was subjected to shear loading [7]. A considerable number of researchers have focused on the responses under the dynamic transverse load or displacement. Sase et al. found that the loosening of fasteners was mainly caused by two factors under a transverse displacement $[8,22]$ : one factor was the relative slip between the threads of the bolt and nut, while the other factor was the relative slip between the bolt (or nut) surface and the surface of the fastened material. The findings of the loosening analysis of bolted joints subjected to dynamic shear load conducted by Pai and Hess indicated that fastener loosening occurred as a result of complete or localized slip at the thread and head contact surfaces $[9,10]$. Fasteners can loosen under lower loads than those previously anticipated because of localized slip at the contact surfaces, which was confirmed by Dinger and Friedrich [11]. Shoji and Sawa found that the relative slip between threads was recurrent, which led to a nut rotation large enough to cause the bolt to loosen [12]. Yang et al. further noted that with the increasing number of load cycles, the relative slip gradually accumulated which continuously reduced the preload and eventually resulted in the failure of the fastening bolts connection [13]. Studies conducted by Jiang and co-workers revealed that the self-loosening process of bolted joints subjected to a transverse displacement could be divided into two distinct stages [14-16]. The first stage did not involve relative rotation between the nut and bolt, and the loosening was caused by material deformation. However, the second stage was characterized by obvious backing-off of the nut and rapid decrease of the clamping force.

Coating and lubrication are often used for reducing the friction coefficients of threaded fasteners [24, 25].
However, the effect of friction coefficients on the loosening process is controversial. On one hand, increased friction coefficient means an increased friction torque for resisting the relative rotation or slip at the thread and head contact surfaces which plays a role on anti-loosening. Daadbin and Chow described a theoretical model for a threaded connection under impact loading [26]. They found that the increase of the friction coefficient decreased the preload loss. Houari [18] and Karamis [27] showed that the increase of the bearing friction reduced the loosening rate. Furthermore, Zaki et al. [19] found that the increase of the coating thickness decreased the friction coefficients of the thread and head bearing, therefore thick coated fasteners would loosen at a faster rate than thin coated fasteners [28]. Sanclemente and Hess discovered that friction coefficients decreased with the application of lubricant which promoted slippage and thereby loosening [20]. However, the study also indicated that when lubrication was applied in combination with higher preload, the resulting effect was beneficial for vibration resistance. On the other hand, the torquetension relationship for threaded fasteners is highly sensitive to the friction coefficient variation between the turning surfaces at the head/nut interface and threads [29]. The decrease of friction coefficients increases the preload under the same initial tightening torque which leads to a better anti-loosening performance. Liu et al. considered adding $\mathrm{MoS}_{2}$ lubricant to bolted joints as a good method to prevent loosening when the bolted joint was subjected to axial excitation [6]. Hence, it is crucial to investigate the effect of coating on the self-loosening of threaded fasteners.

Solid lubricating coatings are highly regarded in scientific and industrial communities due to their excellent friction reduction and wear resistance properties [30]. Coating used on fasteners can change friction coefficient, and thus different coatings have different anti-loosening performance. However, there is very little research on the anti-loosening performance of coatings. Polytetrafluoroethylene (PTFE) is one of the most commonly used solid lubricants that exhibits an ultra-low coefficient of friction [31]. In addition, molybdenum disulfide $\left(\mathrm{MoS}_{2}\right)$ is a popular solid lubricant used widely in machinery equipment to reduce or eliminate various wear damage [32]. Titanium nitride (TiN) coating is also widely used due to its high 
hardness and high adhesion strength that enhance the surface properties under wear and corrosion conditions [33, 34]. Thus, conducting an experimental research to investigate the anti-loosening performance of these typical coatings will provide theoretical support and engineering guidance to prevent loosening of bolt-connected structures.

In this paper, two kinds of typical anti-friction coatings (PTFE and $\mathrm{MoS}_{2}$ ) and anti-wear coating (TiN) are applied to fasteners in order to investigate their anti-loosening performance under dynamic shear load. The evolution curves of the bolts clamping force are obtained and the damages of the thread surfaces in contact are analyzed. This study examines the loosening mechanism as fretting of surface coating and assesses the anti-loosening performance of these typical coatings. In addition, this study also explores the differences in the anti-loosening performance of the three coatings under different load forms.

\section{Experimental details}

\subsection{Test device and parameters}

Self-loosening experiments of fasteners are carried out using the electro-hydraulic servo fatigue testing machine with a custom designed testing fixture under cyclic shear load. A schematic illustration of the test machine is shown in Fig. 1. The upper fixture is connected to the grip of the fatigue testing machine while the lower fixture is fixed to the test stand. The upper and lower fixtures are made of $25 \mathrm{~mm}$ thick 1045 steel and are clamped by a bolt and nut. The load cell is placed between the upper and lower fixtures. It is connected to a data acquisition system to monitor the clamping force in real-time manner. In order to protect the fretting wear of the load cell, two thin washers made of aluminum alloy are placed between the load cell and the bolt testing fixture.

Load-controlled experiments are conducted. The dynamic shear load is the controlling parameter which is applied by the fatigue testing machine and measured by high-precision mechanical sensors.

According to the related standard, an appropriate level of preload corresponds to $60 \%-70 \%$ of the nominal yield strength of the bolt [35]. Accordingly, for M12mm

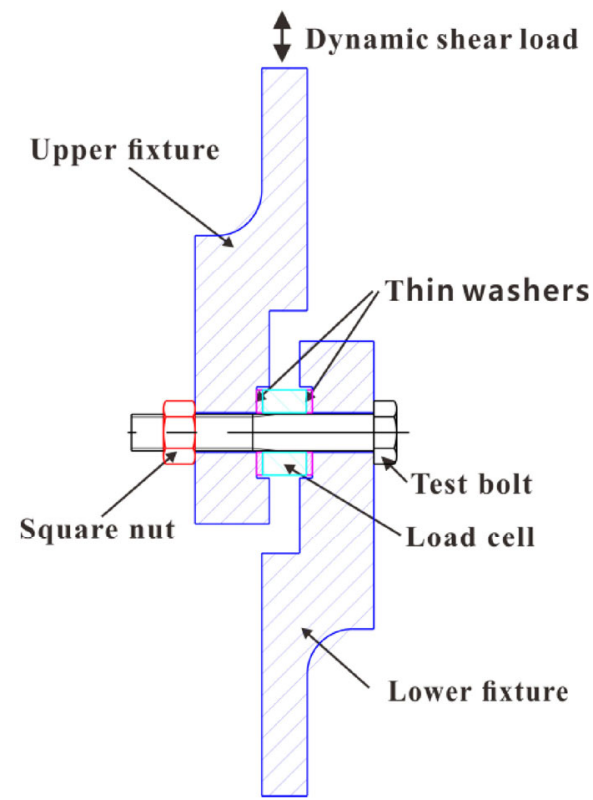

Fig. 1 Schematic of the test machine.

grade- 8.8 bolts, the proper preload ranges from $18.2 \mathrm{kN}$ to $21.2 \mathrm{kN}$. Therefore, the self-loosening experiments in the study are conducted with a preload of $20 \mathrm{kN}$, as a median value between $18.2 \mathrm{kN}$ and $21.2 \mathrm{kN}$. However, in practice, a controlling-torque method is adopted to control the preload. An initial tightening torque $\left(M_{0}\right)$ is applied to achieve a specified torque by slowly tightening the bolt using a digital torque wrench. In order to effectively assess the anti-loosening performance of the different coatings, two groups of experimental parameters are selected: (a) applying the same initial tightening torque $M_{0}=72 \mathrm{~N} \cdot \mathrm{m}$; (b) applying the same preload $P_{0}=20 \mathrm{kN}$.

Preliminary tests of uncoated fasteners for the self-loosening experiment are performed to determine the test parameters. In the preliminary tests, four different dynamic shear load levels are applied in the experiments, which are $\pm 4 \mathrm{kN}, \pm 6 \mathrm{kN}, \pm 7 \mathrm{kN}$, and $\pm 8 \mathrm{kN}$, respectively. It is found that when the shear load is $\pm 4 \mathrm{kN}$, the self-loosening curve is similar to the loosening curve under the shear load of $\pm 6 \mathrm{kN}$. When the shear load increases to $\pm 7 \mathrm{kN}$ or $\pm 8 \mathrm{kN}$, the bolts become completely loosened in less than 5,000 cycles. The reason may be that when the shear load is large enough to overcome the static friction between the two clamping plates, an excessive lateral slippage between them occurs and the clamping force decreases quickly. So the dynamic shear load is selected as $\pm 6 \mathrm{kN}$ in the 
coated fasteners experiments. In the preliminary tests, two loading regimes of 200,000 and 1,000,000 cycles are used and it is found that the self-loosening curve yields similar results. To save time, 200,000 cycles of loading are used in the coated fasteners experiments.

A frequency of $10 \mathrm{~Hz}$ is selected to carry out the tests due to the following reasons: First, $10 \mathrm{~Hz}$ is the frequency commonly used in the field of mechanical engineering. For example, fasteners on train bogies are subjected to an excitation of frequency of about $10 \mathrm{~Hz}$. Secondly, the frequency of $10 \mathrm{~Hz}$ is relatively easy to achieve when using the electro-hydraulic servo fatigue testing machine. Hence, all experiments are conducted with $10 \mathrm{~Hz}$ frequency at room temperature.

\subsection{Preparation and characterization of coatings}

The bolts and nuts used for the purpose of this study are $\mathrm{M} 12 \times 1.75 \mathrm{~mm}$ of grade 8.8 . In order to reduce the dispersion of the preload and loosening values, a number of high-quality bolts and nuts are machined using 1045 steel. Relevant parameters and thread profile of the testing bolts can be found in Ref. [35]. The composition and main characteristics of 1045 steel are listed in Tables 1 and 2, respectively.

Three kinds of typical coatings, PTFE, $\mathrm{MoS}_{2}$, and TiN, are applied to the tested blots and nuts in order to study the effect of these coatings on bolt loosening. As previously mentioned, Zaki et al. [19] found that the increase of the coating thickness decreased the friction coefficient between threads and the friction coefficient between the bolt (or nut) and the bearing surface. Therefore, the coating thickness may affect the loosening behavior and it is necessary to choose the appropriate coating thickness before coating preparation. On one hand, if the coating thickness is too thin, the coating may be worn out quickly during the

Table 1 The chemical composition of 1045 steel (wt.\%).

\begin{tabular}{cccccccc}
\hline Material & $\mathrm{C}$ & $\mathrm{Si}$ & $\mathrm{Mn}$ & $\mathrm{Ni}$ & $\mathrm{Cr}$ & $\mathrm{P}$ & $\mathrm{S}$ \\
1045 Steel & 0.45 & 0.27 & 0.65 & 0.25 & 0.25 & $\leq 0.04$ & $\leq 0.04$ \\
\hline
\end{tabular}

Table 2 The main characteristics of 1045 steel.

\begin{tabular}{ccccc}
\hline Material & $\begin{array}{c}\text { Yield } \\
\text { strength } \\
(\mathrm{MPa})\end{array}$ & $\begin{array}{c}\text { Tensile } \\
\text { strength } \\
(\mathrm{MPa})\end{array}$ & $\begin{array}{c}\text { Elastic } \\
\text { modulus } \\
(\mathrm{GPa})\end{array}$ & $\begin{array}{c}\text { Poisson's } \\
\text { ratio }\end{array}$ \\
\hline 1045 Steel & 650 & 850 & 210 & 0.3 \\
\hline
\end{tabular}

pre-loading process. On the other hand, if the coating is too thick, the fit between the bolt and the nut would be affected, leading to difficulty in applying tightening torque. Thus, a coating thickness of $15 \mu \mathrm{m}$ is selected for the PTFE and $\mathrm{MoS}_{2}$ coatings. However, since the TiN coating is typically considered as an anti-wear coating, the thickness of TiN coating can be appropriately reduced. Thus, the selected thickness for the TiN coating is $5 \mu \mathrm{m}$.

The preparation of the three coatings is as follows: (1) PTFE coating is prepared using a spraying technique. The fine PTFE powders are uniformly dispersed in epoxy adhesive. After descaling, rusting, and sand blasting, the mixture is sprayed onto the surfaces of fasteners by a spray gun. Then, the coating is solidified by heat curing at $200{ }^{\circ} \mathrm{C}$ for 1 hour. The coating thickness is $15 \pm 1 \mu \mathrm{m}$. (2) $\mathrm{MoS}_{2}$ coating is prepared in a similar way to PTFE coating. The thickness of the coating is also $15 \pm 1 \mu \mathrm{m}$. (3) The PVD TiN coating, with thickness of $5 \pm 1 \mu \mathrm{m}$, is deposited on the fasteners by an ion-plating equipment (MIP-800) at a bias voltage of $-100 \mathrm{~V}$ to $-150 \mathrm{~V}$ and a mixed gas $\left(\mathrm{N}_{2}+\mathrm{He}\right)$ pressure of $0.6 \mathrm{~Pa}$. The characteristic parameters of coatings are listed in Table 3.

Figure 2 shows the morphology of the fasteners after the coating treatment. Figure 2(a) shows a cross sectional morphology of the coating/substrate. It can be seen from Fig. 2(a) that the thickness of coatings does not change significantly in the observation range. Figure 2(b) shows the thread surface morphology of the three kinds of coated fasteners. It can be seen that there is no spalling in any of the tested coatings. Based on the above observations, we believe that the three coatings are sufficiently uniform.

All test specimens, screws, washers, and fixtures are cleaned with acetone to remove surface contamination before the self-loosening testing. Some uncoated fasteners are also tested for comparison purposes.

Each self-loosening experiment is repeated five times for coated fasteners and uncoated fasteners at identical

Table 3 The characteristic parameters of coatings.

\begin{tabular}{cccc}
\hline Coatings & Preparation & Thickness $(\mu \mathrm{m})$ & Hardness $(\mathrm{HV})$ \\
\hline PTFE & Spraying & $15 \pm 1$ & $23 \pm 2$ \\
$\mathrm{MoS}_{2}$ & Spraying & $15 \pm 1$ & $60 \pm 5$ \\
TiN & PVD & $5 \pm 1$ & $2,500 \pm 200$ \\
\hline
\end{tabular}



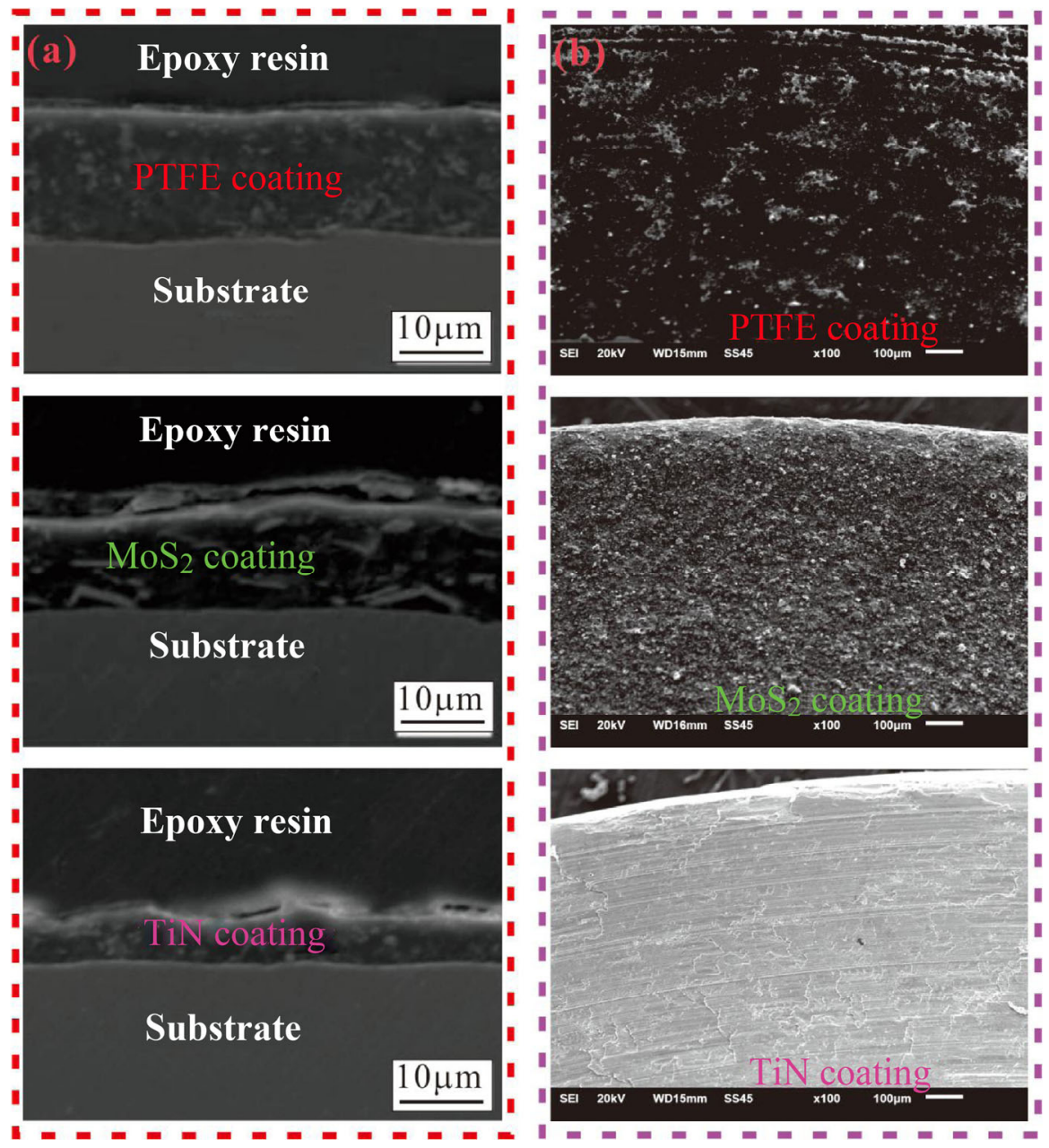

Fig. 2 The morphology of the fastener after coating treatment: (a) the cross sectional morphology of coating/substrate, (b) the thread surface of coated fasteners.

test parameters. After conducting the self-loosening tests, the morphologies of wear scar are examined by a scanning electron microscope (SEM) and the chemical compositions of the damaged zone are analyzed using energy dispersive X-ray (EDX).

\section{Results and discussion}

\subsection{The anti-loosening performance of three coatings}

The loosening degree $(\varphi)$ is defined as the ratio of the loss of preload and the initial preload as expressed by Eq. (1) [20].

$$
\phi=\frac{P_{0}-P_{\mathrm{i}}}{P_{0}} \times 100 \%
$$

where $P_{\mathrm{i}}$ is the remaining preload after the test, $P_{0}$ is the initial preload.

$\varphi$ is a dimensionless variable which is simply a measure or indication of preload loss. A low $\varphi$ value means a slight loosening of bolted fasteners, and thus a better anti-loosening performance, and vice versa.

Figure 3 shows the experimental results of the selfloosening performance of three coated fasteners tested under the same initial tightening torque $M_{0}=72 \mathrm{~N} \cdot \mathrm{m}$. The experimental results are the calculated median value of the repeated test data. It is worth mentioning that the PTFE coated fastener begins slipping when the tightening torque is $60 \mathrm{~N} \cdot \mathrm{m}$. So the initial tightening torque is selected as $60 \mathrm{~N} \cdot \mathrm{m}$ for the PTFE coated fastener.

Figure 3 illustrates that applying different coatings result in quite different anti-loosening performances under the same initial tightening torque. As shown in 

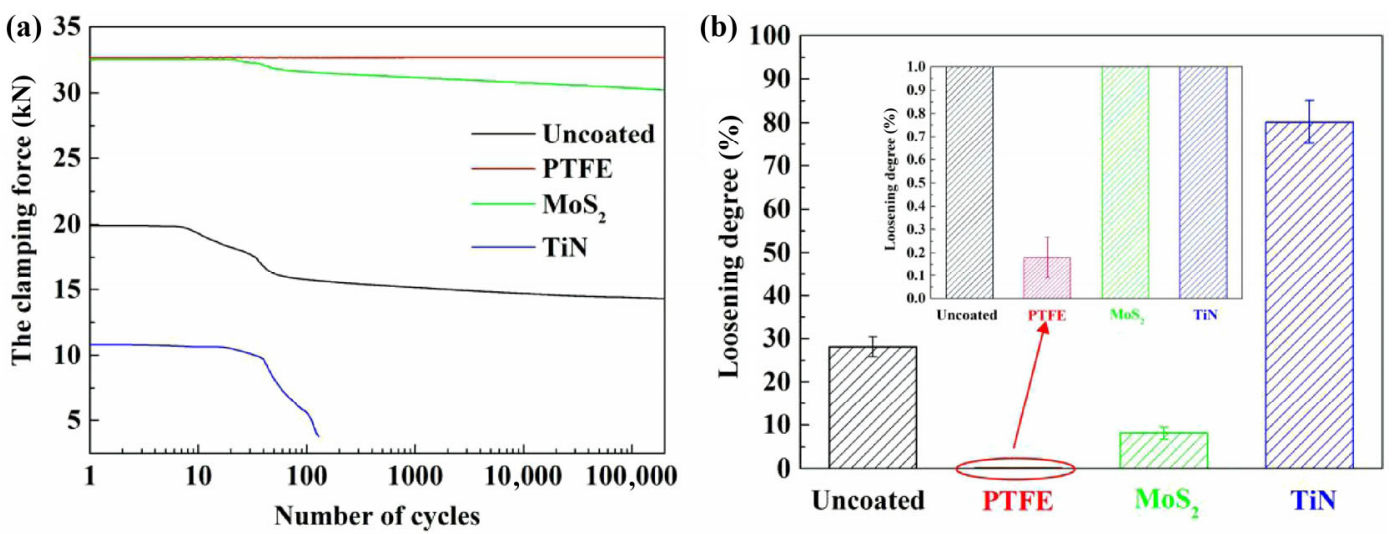

Fig. 3 Self-loosening experimental results of three coatings under the same initial tightening torque: (a) self-loosening curves, (b) loosening degree. $\left(f=10 \mathrm{~Hz}, M_{0}=72 \mathrm{~N} \cdot \mathrm{m}, N=2 \times 10^{5}\right)$

Fig. 3(a), virtually no change in the clamping force of the PTFE coated fasteners is reported, and the loosening degree of PTFE coated fasteners is close to zero (Fig. 3(b)). The clamping force of $\mathrm{MoS}_{2}$ coated fasteners does not obviously decline; with an average loosening degree of only $8.08 \%$, this is considered very slight compared to the $70 \%$ decrease in uncoated fasteners. More importantly, adding PTFE and $\mathrm{MoS}_{2}$ coated fasteners can reduce the scatter of the loosening degree test data, thereby improving the reliability of bolted structures. Additionally, the coatings allow reducing the variance of loosening degree by nearly $85 \%$ compared to uncoated fasteners. These results prove that the PTFE and $\mathrm{MoS}_{2}$ coatings have significant anti-loosening performance.

On the other side, an opposite result is achieved from testing the TiN coating on fasteners. The preload is only $12 \mathrm{kN}$ when the initial tightening torque is $72 \mathrm{~N} \cdot \mathrm{m}$. Although it is shown in Fig. 3(b) that the obtained loosening degree of TiN coated fasteners is around $80 \%$, however, the actual observations during the laboratory experiments indicate a higher loosening degree than $80 \%$. It is observed that when the clamping force decreased to $4 \mathrm{kN}$, the dynamic shear load can no longer be applied and loosening tests were aborted due to the excessive displacement between the upper fixture and lower fixture. It can be concluded that the TiN coating allows complete loosening under the initial tightening torque $\left(M_{0}=72 \mathrm{~N} \cdot \mathrm{m}\right)$. Therefore, a fastener with TiN coating has an insignificant effect on anti-loosening performance under this initial tightening torque.
The anti-loosening performance among the different coatings under the same initial tightening torque is very obvious, which is attributed to the difference in the tightening characteristic of various coatings. It is assumed that the threads friction coefficient $\mu_{\mathrm{t}}$ equals to the friction coefficient between the bolt (or nut) and the bearing surface $\mu_{\mathrm{b}}$ under various experimental parameters. The tightening characteristics of various coatings can be theoretically calculated using Eqs. (2) and $(3)[36,37]$.

$$
\begin{gathered}
M_{0}=K P_{0} d \\
M_{0}=P_{0}\left(\frac{P}{2 \pi}+\frac{\mu_{\mathrm{t}} r_{\mathrm{t}}}{\cos \beta}+\mu_{\mathrm{b}} r_{\mathrm{b}}\right)
\end{gathered}
$$

where $M_{0}$ is the tightening torque applied to the bolt head/nut; $P_{0}$ is the preload; $K$ is the nut factor; $P$ is the thread pitch; $\beta$ is half of the thread flank angle; $d$ is the basic pitch diameter of thread; $\mu_{\mathrm{t}}$ is the friction coefficient between threads; $\mu_{\mathrm{b}}$ is the friction coefficient between the bolt (or nut) and the bearing surface; $r_{t}$ is the effective contact radius between threads; $r_{\mathrm{b}}$ is the effective bearing radius of the bearing contact area under the turning head or nut. The dimensions of the bolts used in this series of tests are listed in Table 4 .

Figure 4 shows the tightening characteristics of various coatings. It is observed from Fig. 4 that coatings have a significant effect on the nut factor and friction coefficients in threaded fasteners. PTFE coating and $\mathrm{MoS}_{2}$ coating can effectively reduce the nut factor and friction coefficients which decreases by nearly $50 \%$ compared to uncoated fasteners. Thus, as shown in 
Fig. 5, under the same initial tightening torque, the initial preload of fasteners with PTFE coating or $\mathrm{MoS}_{2}$ coating is approximately double that of uncoated fasteners; and applying a higher preload leads to reduced loosening or no loosening $[8,15,20]$. While the initial preload of the TiN coating fasteners is only half of that of uncoated fasteners. Under a lower preload, the friction force decreases and the shear force easily overcomes the friction force and the occurrence

Table 4 Bolt dimensional details.

\begin{tabular}{lc}
\hline Parameters & Value \\
\hline Thread diameter, $d$ & $12 \mathrm{~mm}$ \\
Thread pitch, $p$ & $1.75 \mathrm{~mm}$ \\
The thread flank angle, $\alpha$ & $60^{\circ}$ \\
The outer bearing diameter, $D_{0}$ & $18.0 \mathrm{~mm}$ \\
The hole diameter of the clamped body, $d_{0}$ & $13.0 \mathrm{~mm}$ \\
The effective thread radius, $r_{\mathrm{t}}$ & $5.43 \mathrm{~mm}$ \\
The effective bearing radius, $r_{\mathrm{b}}$ & $7.82 \mathrm{~mm}$ \\
\hline
\end{tabular}
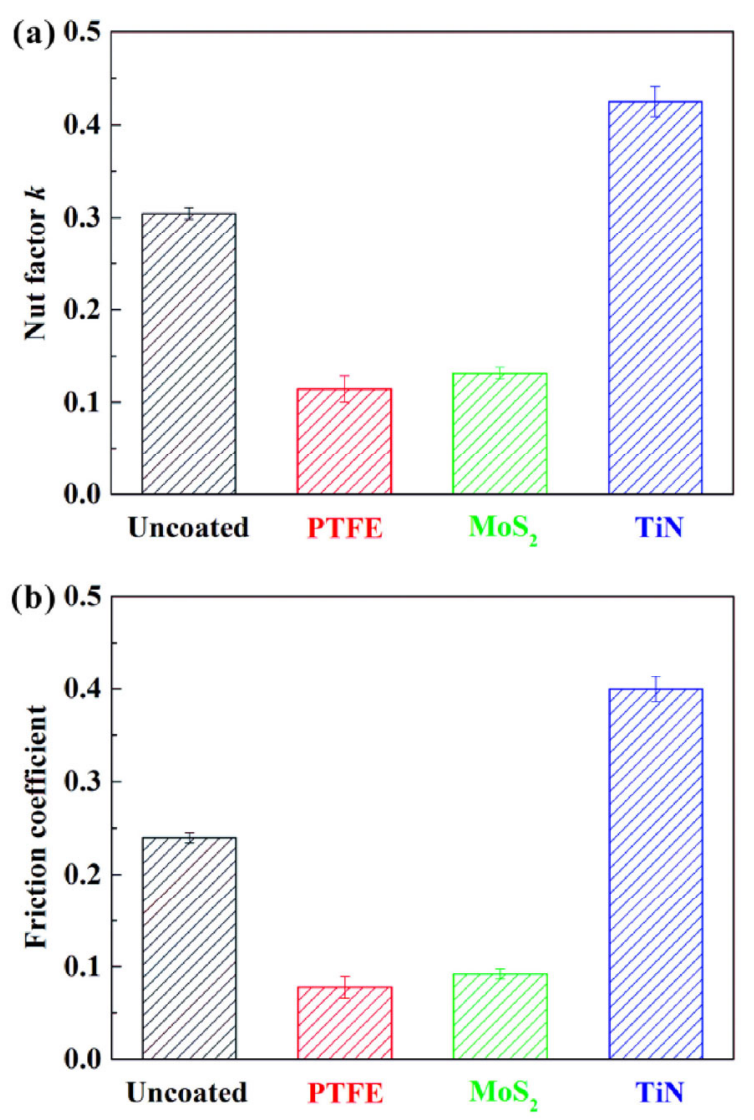

Fig. 4 The tightening characteristics of various coatings: (a) nut factor $k,(\mathrm{~b})$ friction coefficients.

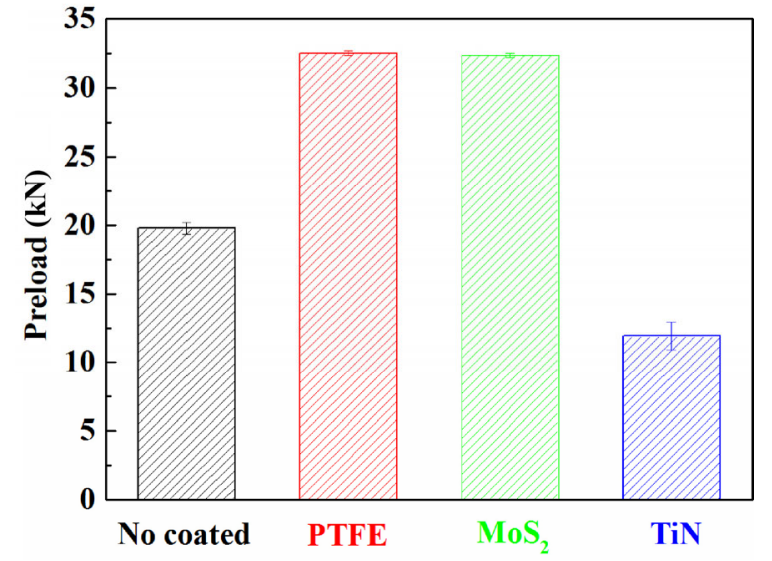

Fig. 5 The preload of coated fasteners under the same initial tightening torque.

of slippage increases, causing the rapid decrease of the clamping force and even complete looseness of fasteners (Fig. 3(a)).

Figure 6 shows the experimental results of selfloosening performance of the three coated fasteners under the same preload $P_{0}=20 \mathrm{kN}$. It should be noted that the nut factor of TiN coating is so high that the fasteners are distorted before the preload reaches $20 \mathrm{kN}$. In several experiments, the preload can only be applied to approximately $19 \mathrm{kN}$. Thus, the initial preload of $19 \mathrm{kN}$ is selected for TiN coated fasteners.

Figure 6(a) shows the clamping force reduction in relation to the number of cycles. As shown in Fig. 6(a), it is experimentally observed that a typical selfloosening process due to dynamic shear load can be divided into three distinct stages including a stable stage, a rapid declining stage, and a slow declining stage.

(1) The first stage: at the beginning of the experiment up to around the $50^{\text {th }}$ cycle, the clamping force is nearly constant. The duration of this stage is not long (only about $5 \mathrm{~s}$ ), as it takes a few seconds for the testing machine to achieve $6 \mathrm{kN}$ (the amplitude of the dynamic shear load). From the beginning of the experiment to obtaining the amplitude of shear load takes a short time which corresponds to this stage.

(2) The second stage: from $50^{\text {th }}$ cycle to about $2,000^{\text {th }}$ cycle, the clamping force decreases significantly. This stage corresponds to the second stage of the selfloosening process of bolted joints subjected to a transverse displacement investigated by Jiang and 

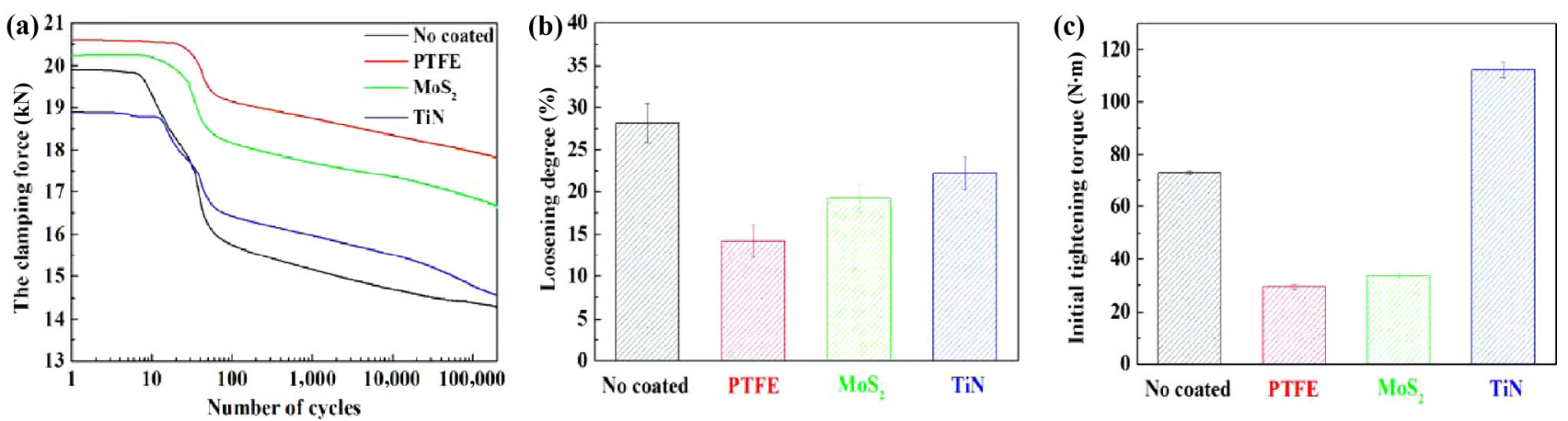

Fig. 6 The self-loosening experimental results of coated fasteners under the same preload: (a) self-loosening curves, (b) loosening degree, (c) initial tightening torque. $\left(f=10 \mathrm{~Hz}, P_{0}=20 \mathrm{kN}, N=2 \times 10^{5}\right)$

co-workers [14-16]. Liu et al. [6] and Yu et al. [38] found that the self-loosening process of bolted joints under axial excitation also experienced this stage. Previous research showed that the obvious backing-off of the nut $[14,15]$ and the removal of asperities on contact surfaces in this stage led to reduction of the clamping force. In addition, the dynamic shear load generates slippage between the two clamped plates which reduced the clamping force.

(3) The third stage: from $2,000^{\text {th }}$ cycles to $200,000^{\text {th }}$ cycles, the clamping force slowly decreases. This may be because of the occurrence of localized slip, so-called partial slip in fretting, at the thread and head contact surfaces under dynamic shear load [10,11]. Fretting leads to a stable friction coefficient and wear, thereby the clamping force declines slowly.

Figures 6(b) and 6(c) show the average and variance of the loosening degree and the initial tightening torque. It can be noticed in Fig. 6(b) that applying different coatings result in very different anti-loosening performance under the same preload. In terms of loosening degree, PTFE has the best anti-loosening performance while TiN is the worst. The reported average of loosening degree of PTFE and $\mathrm{MoS}_{2}$ coated fasteners is respectively $14.17 \%$ and $19.20 \%$, which is nearly $40 \%$ lower than that of uncoated fasteners. While the average of loosening degree of TiN coated fasteners is $22.16 \%$ which is slightly decreased compared to uncoated fasteners. More importantly, adding PTFE and $\mathrm{MoS}_{2}$ coating can reduce the scatter of the loosening degree test data. The variance of loosening degree of PTFE and $\mathrm{MoS}_{2}$ coated fasteners decreases nearly $30 \%$ compared to uncoated fasteners.
Considering the difficulty of generating the same preload $P_{0}=20 \mathrm{kN}$, as shown in Fig. 6(c), the preload of the PTFE coated fasteners can be obtained at a low initial tightening torque level, whereas the TiN coated fasteners cannot obtain the same preload at such a low level of initial tightening torque.

Therefore, applying PTFE or $\mathrm{MoS}_{2}$ coating not only reduces the loosening degree but also reduces the scatter of test data of the loosening degree thereby improving the reliability of bolted structures. This may be because adding PTFE or $\mathrm{MoS}_{2}$ coating causes the friction coefficients and asperity to decrease, thereby the contact area increases and the plastic deformation decreases under the same dynamic shear load. Thus, the residual axial clamping force increases and the loosening degree decreases. Previous studies in the field have shown that a steel surface coated with a PVD TiN coating has a higher roughness [34]. Hence, the contact areas of TiN coated fasteners are relatively small; thereby, the plastic deformation increases under the same dynamic shear load. In addition, the nut factor of TiN coating is so high that it needs to be applied with a relatively high initial tightening torque in order to generate the required preload, which results in increasing the plastic deformation of the threaded surface. Thus, the residual axial clamping force decreases while the loosening degree increases.

Furthermore, when comparing Fig. 3(b) and Fig. 6(b), it can be seen that the anti-loosening performance is more significant under a higher initial tightening torque. When the initial tightening torque is $60 \mathrm{~N} \cdot \mathrm{m}$, as shown in Fig. 3(b), the loosening degree of the 
PTFE coated fasteners is close to zero which indicates that the anti-loosening performance of PTFE coating is extremely significant. As shown in Fig. 6(b), when the initial tightening torque decreases to $30 \mathrm{~N} \cdot \mathrm{m}$, an increased loosening degree is reported at $14.17 \%$, which indicates that the anti-loosening performance decreases under a lower initial tightening torque. When the initial tightening torque $\left(M_{0}\right)$ is $72 \mathrm{~N} \cdot \mathrm{m}$, the degree of loosening of $\mathrm{MoS}_{2}$ coated fasteners is only $8.08 \%$ (Fig. 3(b)). However, when the initial tightening torque decreases to $35 \mathrm{~N} \cdot \mathrm{m}$, the degree of loosening is reported at $19.20 \%$, more than double that reported under a higher tightening torque. TiN coated fasteners exhibit complete loosening under the lower initial tightening torque $\left(M_{0}=72 \mathrm{~N} \cdot \mathrm{m}\right)$. When the initial tightening torque increases to $110 \mathrm{~N} \cdot \mathrm{m}$, the loosening degree of TiN coated fasteners is reported at $22.16 \%$, which indicates that adding TiN coating on fasteners has a certain anti-loosening performance under higher initial tightening torque.

\subsection{SEM investigation}

It is reported that the distribution of axial load along a fastener is highly uneven and that the first three threads bear about $70 \%$ of the total axial load while the first thread carries more than $30 \%[39,40]$. Past research indicated that the degree of thread surface damage decreased with the increase of working thread ring $[38,41]$. Thus, the damage of the first thread is analyzed using SEM and EDX.

Figure 7 shows the SEM morphologies and EDX patterns corresponding to the wear scar of the first thread surface of the uncoated fasteners. As shown in
Fig. 7, it can be seen that the regions near the top of the thread show serious furrow while other regions show significant delamination. The EDX analyses of wear scars show that point B presents a higher O-element peak than that of point A. Therefore, the main wear mechanism of the uncoated fasteners is abrasive wear, delamination, and a slight oxidation wear which are typical characteristics of fretting [42].

Figure 8 shows the SEM morphologies and EDX patterns corresponding to wear scars of the first thread surface of the PTFE coated fasteners under different initial tightening torques.

As can be seen in Fig. 8, when the initial tightening torque decreases, the damage of PTFE coated fasteners exacerbates. While Fig. 8(a) shows that under a higher initial tightening torque, the damage of PTFE coated fasteners is reported as slight abrasion and exfoliation in the edge regions. When the initial tightening torque decreases to $30 \mathrm{~N} \cdot \mathrm{m}$, serious wear is observed, as shown in Fig. 8(b). Nearly half of the coating may be removed. Seriously damaged areas are observed on the thread edge and it is found that these regions show serious furrow and significant delamination. The EDX analyses of wear scars show that a small amount of O-element is present at point $\mathrm{A}$ and point B. This may be due to the slight oxidation reaction occurs at the threaded surface before the application of coating. It may also be caused by the oxidation wear during experiments. Therefore, the main wear mechanisms of PTFE coated fasteners are fatigue wear, abrasive wear, and slight oxidation wear, which are in accordance with the typical characteristics of fretting that means fretting wear occurs on the bolt (a)

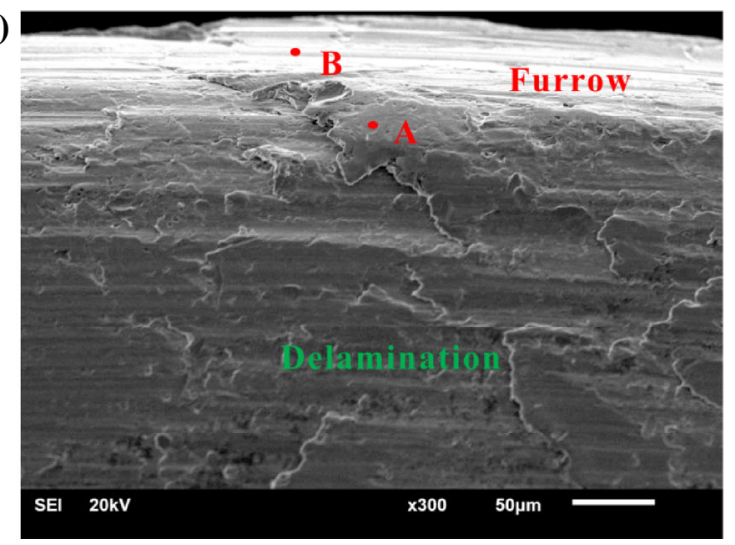

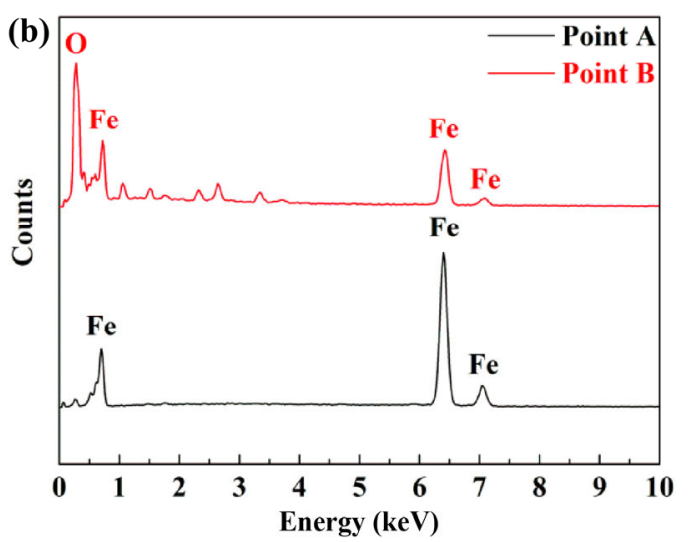

Fig. 7 Microscopic damage for uncoated fasteners: (a) SEM micrograph, (b) EDX spectrum corresponding to point A and point B. 


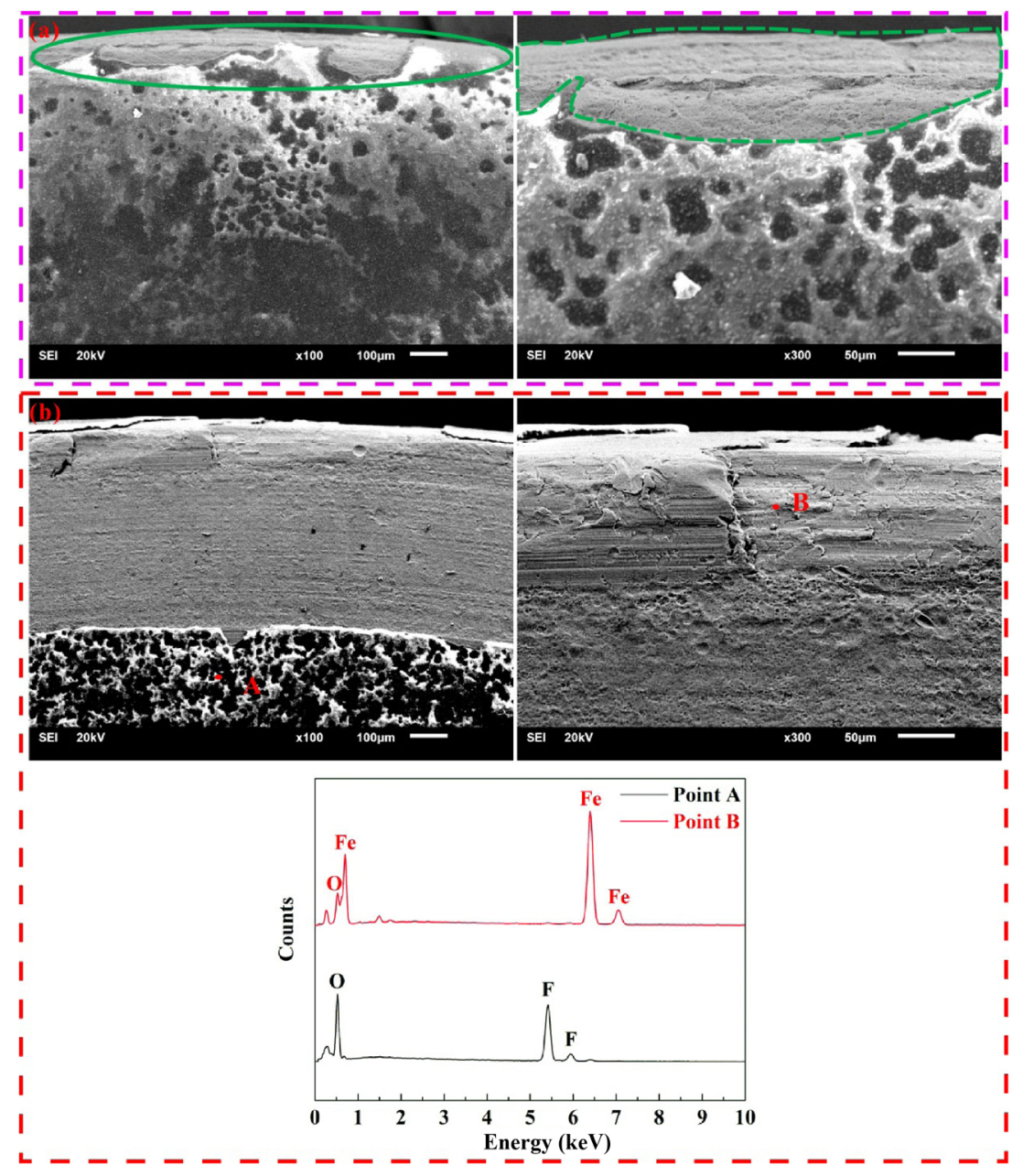

Fig. 8 Microscopic damage for PTFE coated fasteners under (a) initial tightening torque $M_{0}=60 \mathrm{~N} \cdot \mathrm{m}$, (b) initial tightening torque $M_{0}=30 \mathrm{~N} \cdot \mathrm{m}$.

contact surfaces. Fretting exacerbates damage and leads to a higher loosening degree which indicates that loosening of bolts is closely related to fretting.

Figure 9 shows the SEM morphologies and EDX patterns are corresponding to the wear scar of the first thread surface of the $\mathrm{MoS}_{2}$ coated fasteners under different initial tightening torques. Similar to PTFE coated fasteners, with the decrease of initial tightening torque, the damage of $\mathrm{MoS}_{2}$ coated fasteners also exacerbates. However, Fig. 9(a) shows that under a higher initial tightening torque, slight abrasion is observed in the $\mathrm{MoS}_{2}$ coated fasteners, while small areas exhibit exfoliation, mainly at the edge. When the initial tightening torque decreases to $35 \mathrm{~N} \cdot \mathrm{m}$, discontinuous damage of $\mathrm{MoS}_{2}$ coated fasteners is reported, as shown in Fig. 9(b). In the parts, denoted as area (I), the material components of point (A) are analyzed. It is found that the region contains only iron and carbon which suggests that coating of the bolt has been completely removed. The damaged surface in this area shows obvious plastic furrow and delamination phenomenon. In other parts, denoted as area (II), the coating displays relatively minor abrasion. The EDX analyses of wear scars show that point (B) presents Mo-element and S-element which indicates that $\mathrm{MoS}_{2}$ coating has a good self-lubricating effect. Meanwhile, a small amount of O-element is present at point (B). This may be due to oxidation wear during the experiments. Therefore, the main wear mechanism of $\mathrm{MoS}_{2}$ coated fasteners is fatigue wear, abrasive wear, oxidation wear, and delamination which are in accordance with the typical characteristics of 


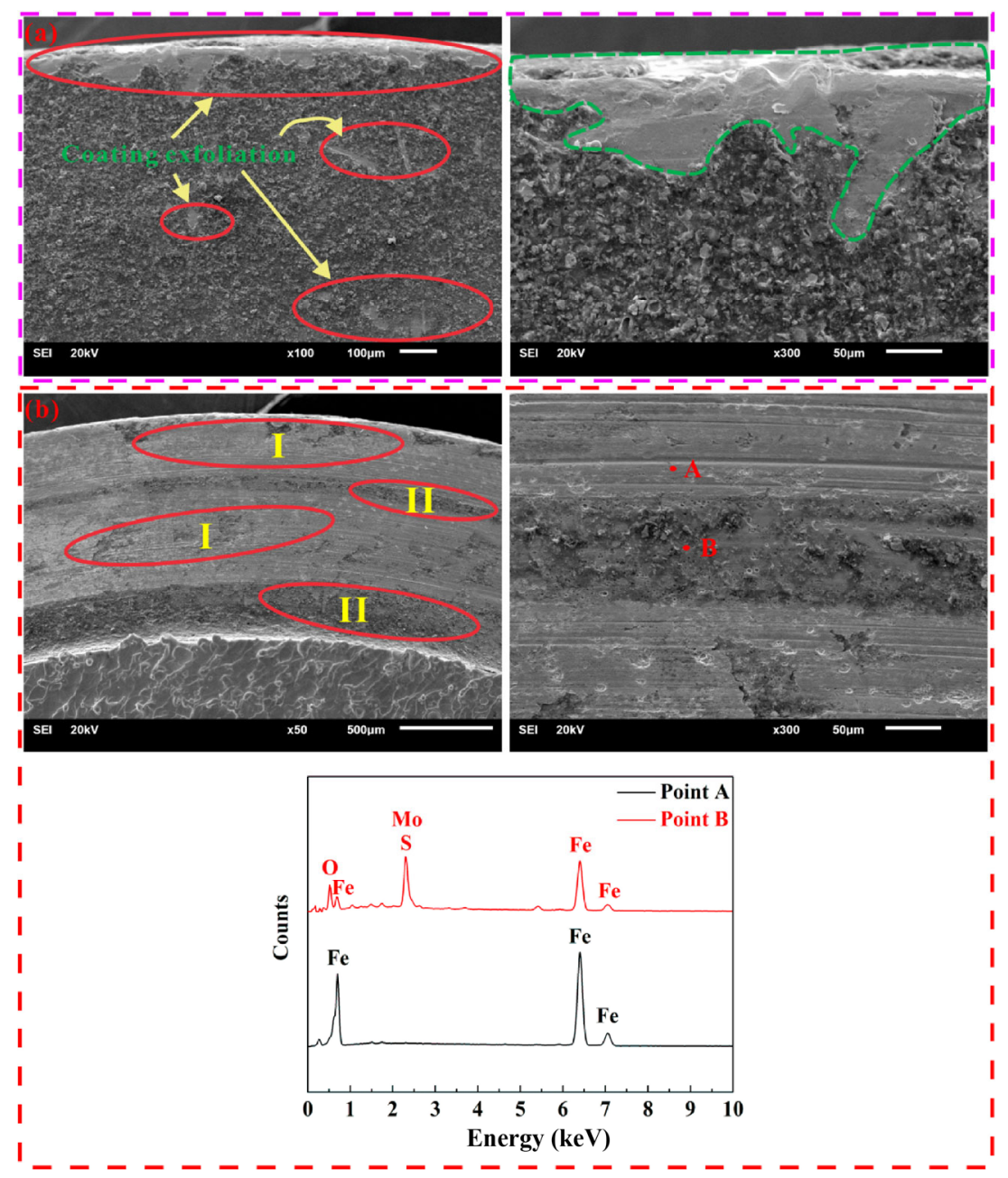

Fig. 9 Microscopic damage for $\mathrm{MoS}_{2}$ coated fasteners under (a) initial tightening torque $M_{0}=72 \mathrm{~N} \cdot \mathrm{m}$, (b) initial tightening torque $M_{0}=35 \mathrm{~N} \cdot \mathrm{m} \cdot\left(f=10 \mathrm{~Hz}, N=2 \times 10^{5}\right)$

fretting. Fretting exacerbates damage and leads to a higher loosening degree which indicates that the loosening of bolts is closely related to fretting.

With regard to TiN coatings, it is reported that some TiN coated bolts are distorted during the test. The reason of distortion of TiN coated bolts is that the nut factor of TiN coated fasteners is so high that in order to achieve the same preload, the required tightening torque needs to be higher than that for uncoated fasteners. As can be seen in Fig. 6, an approximate preload of only $19 \mathrm{kN}$ can be applied to the TiN coated fasteners, while the initial tightening torque is approximately $110 \mathrm{~N} \cdot \mathrm{m}$. Such high tightening torque may result in a greater frictional stress between the thread contact surfaces. In fact, the bolts undergo serious plastic deformation under such loading con- dition or may even fracture. It is observed that some TiN coated fasteners are difficult to unscrew after loosening testing because of the distortions or fractures (Fig. 10). Therefore, adding TiN coating on fasteners gains a certain anti-loosening performance under the same preload (Fig. 6), however it is not an ideal method to prevent loosening.

\subsection{Effects of loading form}

Many studies show that loosening is more severe when a joint is subjected to transverse alternating loading than axial alternating loading $[7,17]$. However, the anti-loosening performance of coated fasteners under the two alternating loading forms has not been reported in the open literature. The authors' research team systematically studied the dynamic behavior of 

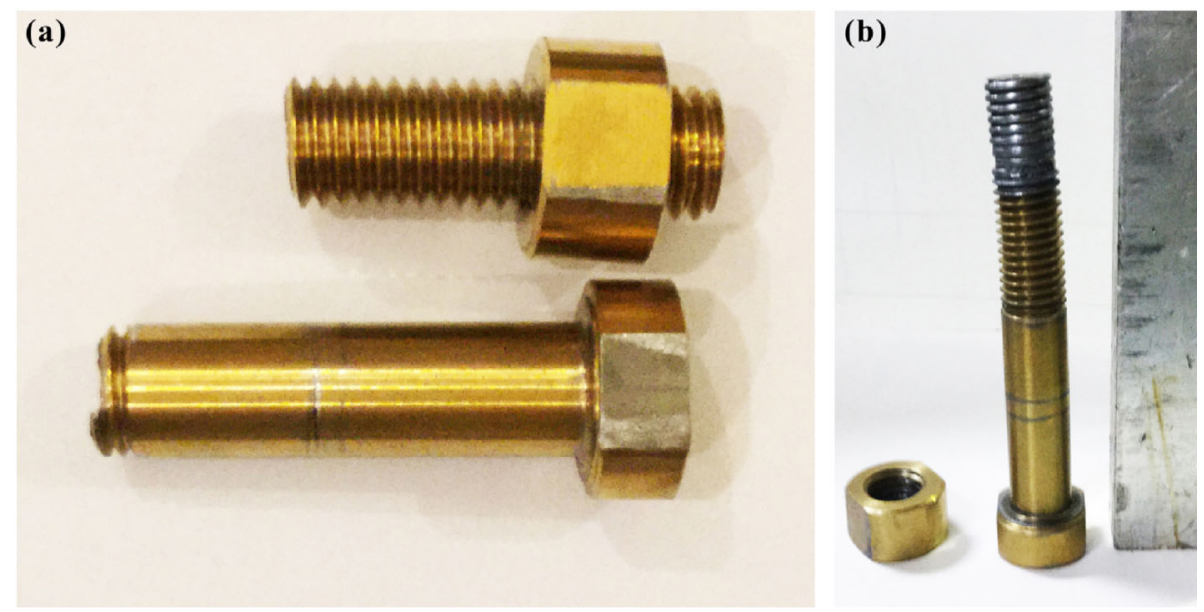

Fig. 10 TiN coated fasteners after loosening tests: (a) fracture, (b) distortion.

coated fasteners under axial excitation using experimental and numerical methods [43]. The aim of this work is to explore the differences in the anti-loosening performances of three coated fasteners under dynamic shear load and axial load. Figure 11 shows the loosening degrees of three coated fasteners under the two different loading forms.

It is obvious in Fig. 11 that different load forms result in different anti-loosening performance of coatings. On one hand, when coated fasteners are subjected to shear load, three kinds of coatings demonstrate obvious anti-loosening performances. PTFE coating has the best anti-loosening performance while TiN coating shows the worst. On the other hand, when the coated fasteners are subjected to axial loading, the anti-loosening performance of $\mathrm{MoS}_{2}$ coating is somewhat encouraging, while TiN coating is still the worst with its loosening degree being reported even higher than those of uncoated fasteners. PTFE coating possesses relatively poor anti-loosening capability compared to uncoated fasteners.

In addition, as shown in Fig. 11, it can also be concluded that the loosening degree is more severe when the fasteners are subjected to shear load than axial load, especially for uncoated and $\mathrm{MoS}_{2}$ coated fasteners. This is possibly because the shear load is acting in the same direction as the relative slip, and thus is more likely to cause relative slip, which may lead to fretting damage.

In actual situations, fasteners are likely to withstand both axial and shear loads. In order to investigate the

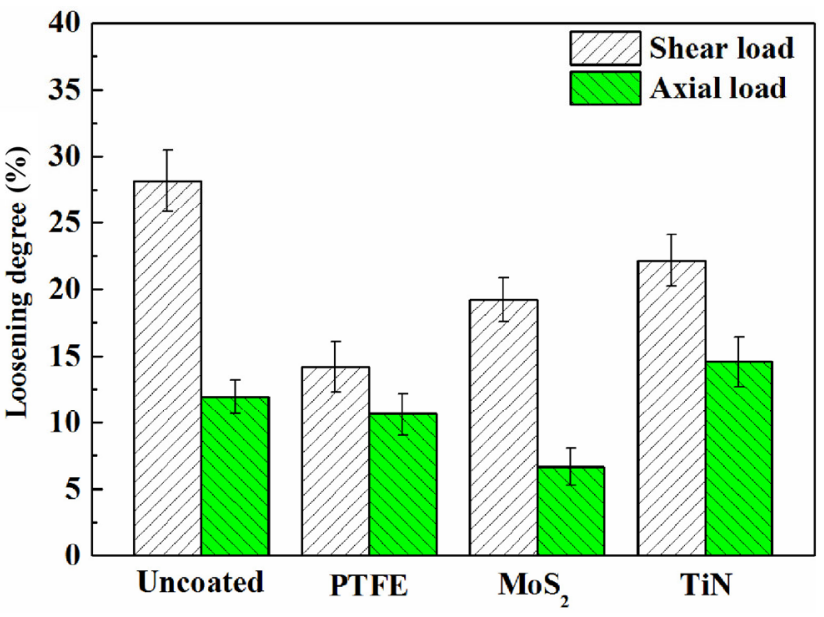

Fig. 11 The loosening degree under different loading forms.

effect of the direction of the externally applied load, Zhang et al. [17] designed an experimental fixture which could change the angle between the directions of the applied force in relation to the contact surface of the two clamped plates. An angle of $0^{\circ}$ represents the pure shear or transverse loading while an angle of $90^{\circ}$ represents axial loading. A $30^{\circ}$ angle applies to both axial and shear loads. The results suggest that an axial load component greatly enhances the resistance of the bolted joints to self-loosening. However, their work shows that fatigue dominates the failure under axial load component. Hence, fatigue strength may become a great concern when there is a large axial load component.

In summary, compared to fasteners subjected to shear load, when fasteners withstand both axial and 
shear loads at the same time, the risk of loosening may be reduced; however, fatigue risk is possible. Such a phenomenon is worth further investigation in future research.

\section{Conclusions}

Based on the results obtained by a series of experiments on fasteners with three different kinds of coatings under different initial tightening torques and dynamic load forms, the following conclusions can be drawn.

(1) PTFE coating and $\mathrm{MoS}_{2}$ coating have significant anti-loosening capabilities which are further enhanced under higher initial tightening torques. However, the anti-loosening performance of the TiN coating is not entirely satisfactory.

(2) The loosening curve can generally be divided into three stages: a stable stage, a rapidly declining stage, and a slowly declining stage.

(3) The loosening mechanism of the coated fasteners is related to fretting under dynamic shear load. Fretting aggravates wear which can readily cause loosening.

(4) The anti-loosening performance of the coatings exhibits obvious differences under shear load and axial load, respectively. The loosening degree is more severe when the fasteners are subjected to shear load than axial load, especially uncoated fasteners and $\mathrm{MoS}_{2}$ coated fasteners.

\section{Acknowledgments}

The authors gratefully acknowledge the financial support provided by the National Science Funds for Distinguished Young Scholars (No. 51025519), the Changjiang Scholarships and Innovation Team Development Plan (No. IRT1178), and the Self-Topic Fund of Traction Power State Key Laboratory (No. 2016TPL-Z03).

Open Access: The articles published in this journal are distributed under the terms of the Creative Commons Attribution 4.0 International License (http:// creativecommons.org/licenses/by/4.0/), which permits unrestricted use, distribution, and reproduction in any medium, provided you give appropriate credit to the original author(s) and the source, provide a link to the Creative Commons license, and indicate if changes were made.

\section{References}

[1] Goodier J N, Sweeney R J. Loosening by vibration of threaded fastenings. Mech Eng 67: 794-800 (1945)

[2] Basava S, Hess D P. Bolted joint clamping force variation due to axial vibration. Sound and Vibration 210(2): 255-265 (1998)

[3] Sakai T. Mechanism for a bolt and nut self-loosening under repeated bolt axial tensile load. Solid Mechanics and Materials Engineering 5(11): 627-639 (2011)

[4] Nassar S A, Yang X X, Gandham S V T, Wu Z J. Nonlinear deformation behavior of clamped bolted joints under a separating service load. Journal of Pressure Vessel Technology 133(2): 021001 (2011)

[5] Yang X X, Nassar S A, Wu Z J, Meng A D. Nonlinear behavior of preloaded bolted joints under a cyclic separating load. Journal of Pressure Vessel Technology 134(1): 011206 (2012)

[6] Liu J H, Ouyang H J, Peng J F, Zhang C B, Zhou P Y, Ma L J, Zhu M H. Experimental and numerical studies of bolted joints subjected to axial excitation. Wear 346-347: 66-77 (2016)

[7] Junker G H. New criteria for self-loosening fasteners under vibration. SAE, Transactions 78: 314-335 (1969)

[8] Sase N, Nishioka K, Koga S, Fujii H. An anti-loosening screw-fastener innovation and its evaluation. Materials Processing Technology 77: 209-215 (1998)

[9] Pai N G, Hess D P. Three-dimensional finite element analysis of threaded fastener loosening due to dynamic shear load. Engineering Failure Analysis 9: 383-402 (2009)

[10] Pai N G, Hess D P. Experimental study of loosening of threaded fastener due to dynamic shear loads. Sound and vibration 253(3): 585-602 (2002)

[11] Dinger G, Friedrich C. Avoiding self-loosening failure of bolted joints with numerical assessment of local contact state. Engineering Failure Analysis 18(8): 2188-2200 (2011)

[12] Shoji Y, Sawa T. Analytical research on mechanism of bolt loosening due to lateral loads. In ASME Pressure Vessels and Piping Division Conference, Denver, Colorado, USA, 2005.

[13] Yang G X, Xie J L, Xie Y Y. Study on mechanism of anti-loosening of a new type of nut based on fem. (in Chinese). Engineering mechanics 12: 224-243 (2010)

[14] Jiang Y, Zhang M, Chu-Hwa Lee. A study of early stage self-loosening of bolted joints. Mechanical Design 125(3): 518-526 (2003) 
[15] Jiang, Y, Zhang M, Park T-W, Lee C-H. An experimental study of self-loosening of bolted joints. Mechanical Design 126(5): 925-931 (2004)

[16] Zhang M, Jiang Y, Lee C-H. Finite element modeling of self-loosening of bolted joints. Mechanical Design 129(2): 218-266 (2007)

[17] Zhang M, Jiang Y, Lee C H. An experimental investigation of the effects of clamped length and loading direction on self-loosening of bolted joints. Journal of Pressure Vessel Technology 128(3):129-136 (2004)

[18] Housari B A, Nassar S A. Effect of thread and bearing friction coefficients on the vibration-induced loosening of threaded fasteners. Journal of Vibration and Acoustics 129(4): 484-494 (2007)

[19] Zaki A M, Nassar S A, Yang X. Effect of thread and bearing friction coefficients on the self-loosening of preloaded countersunk-head bolts under periodic transverse excitation. Journal of Tribology 132(3): 031601-1 (2010)

[20] Sanclemente J A, Hess D P. Parametric study of threaded fastener loosening due to cyclic transverse loads. Engineering Failure Analysis 14: 239-249 (2007)

[21] Anirban B, Avijit S, Santanu D. An investigation on the anti-loosening characteristics of threaded fasteners under vibratory conditions. Mechanism and Machine Theory 45: 1215-1225 (2010)

[22] Sase N, Fujii H. Optimizing study of SLBs for higher anti-loosening performance. Materials Processing Technology 119: 174-179 (2001)

[23] Izumi S, Yokoyama T, Kimurab M, Sakaia S. Looseningresistance evaluation of double-nut tightening method and spring washer by three-dimensional finite element analysis. Engineering Failure Analysis 16(5): 1510-1519 (2009)

[24] Zou Q, Sun T S, Nassar S A, Barber G C, Gumul A K. Effect of lubrication on friction and torque-tension relationship in threaded fasteners. In STLE/ASME International Joint Tribology Conference San Antonio, TX, USA, 2006.

[25] Housari, B A, Nassar, S A. Effect of thread and bearing friction coefficients on the vibration-induced loosening of threaded fasteners. Vibration and Acoustics 129: 484-494 (2007)

[26] Daadbin A, Chow Y M. A theoretical model to study thread loosening. Mechanics and Machine Theory 27: 69-74 (1992)

[27] Karamiş M B, Selçuk B. Analysis of the friction behavior of bolted joints. Wear 166(1): 73-83 (1993)

[28] Nassar S A, Zaki A M. Effect of coating thickness on the friction coefficients and torque-tension relationship in threaded fasteners. Journal of Tribology 31: 021301-1 (2009)
[29] Bickford J H. Introduction to the Design and Behavior of Bolted Joints (4th ed). The Chemical Rubber Company Press, Florida, 2007.

[30] Fan X Q, Xue Q J, Wang L P. Carbon-based solid-liquid lubricating coatings for space applications-A review. Friction 3(3): 191-207 (2015)

[31] Yuan X D, Yang X J. A study on friction and wear properties of PTFE coatings under vacuum conditions. Wear 269: 291-297 (2010)

[32] Luo J, Zhu M H, Wang Y D, Zheng J F, Mo J L. Study on rotational fretting wear of bonded $\mathrm{MoS}_{2}$ solid lubricant coating prepared on medium carbon steel. Tribology International 44: 1565-1570 (2011)

[33] Shan L, Wang Y X, Li J L, Li H. Wu X D, Chen J M. Tribological behaviours of PVD TiN and TiCN coatings in artificial seawater. Surface \& Coatings Technology 226: 40-50 (2013)

[34] Paskvale S, Remškar M, Čekada M. Tribological performance of TiN, TiAlN and CrN hard coatings lubricated by $\mathrm{MoS}_{2}$ nanotubes in Polyalphaolefin oil. Wear 352-353: 72-78 (2016)

[35] Cheng D X. Handbook of Mechanical Design. (in Chinese). Beijing: Chemical Industry Press, 2016.

[36] Nassar S A, El-Khiamy H, Barber, G C, Zuo D J, Sun T S. An experimental study of bearing and thread friction in fasteners. Journal of Tribology 127(2): 263-272 (2005)

[37] Nassar S A, Barber G C, Zuo D J. Bearing friction torque in bolted joints. Tribology Transactions 48: 69-75 (2005)

[38] Yu Z T, Liu J H, Zhang C Q, Zhou J B, Peng J F, Ma L J, Zhu M H. An experimental study on self-Loosening of bolted joints under axial vibration. (in Chinese). Tribology 35(6): 732-736 (2015)

[39] Yamamoto A. Theory and Calculation of Thread Connection. (in Chinese). Translated by Guo K Q, Gao S J, Wang X F, $\mathrm{Xu}$ A L. Shanghai: shanghai scientific and technological literature press, 1982.

[40] Zhao H. Analysis of the load distribution in a bolt-nut connector. Computers and Structures 53(6): 1465-1472 (1994)

[41] Liu J H, Ouyang H J, Ma L J, Zhang C Q, Zhu M H. Numerical and theoretical studies of bolted joints under harmonic shear displacement. Latin American Journal of Solids and Structures 12(1): 115-132 (2015)

[42] Zhou Z R, Zhu M H. Dual-fretting Wear. (in Chinese). Shanghai: Shanghai Jiaotong University Press, 2004.

[43] Liu J H. Research on the self-loosening mechanism of bolted joints under axial excitation. Ph. D Thesis. Sichuan (China): Southwest Jiaotong University, 2016. 


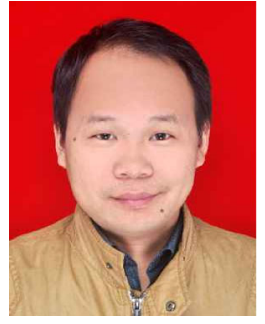

Junbo ZHOU. He received his master degree in mechanical engineering in 2009 from Wuhan University of Technology, Hubei, China. After then, he worked in

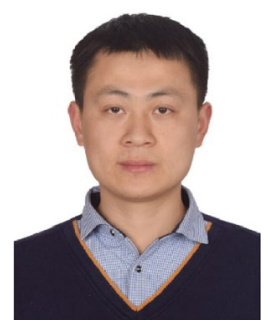

Jianhua LIU. He received his bachelor degree and $\mathrm{PhD}$ degree from Southwest Jiaotong University, Sichuang, China, in 2010 and 2016,

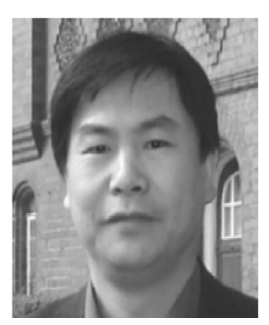

Huajiang OUYANG. He received his bachelor degree, master degree and $\mathrm{PhD}$ degree from Dalian University of Technology, China, in 1982, 1985 and 1989, respectively. He is a full professor in the School

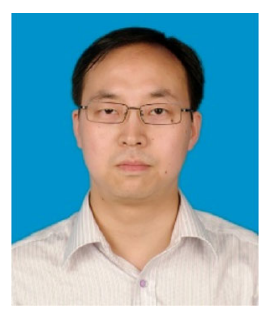

Zhenbing CAI. He received his bachelor degree and $\mathrm{PhD}$ degree from Southwest Jiaotong University, Sichuang, China, in 2003 and 2009, respectively. $\mathrm{He}$ is currently a

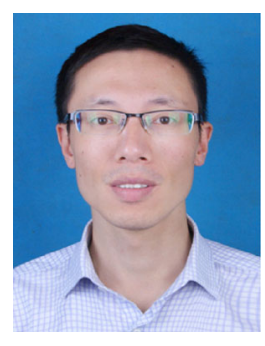

Jinfang PENG. He received his bachelor degree and $\mathrm{PhD}$ degree from Southwest Jiaotong University, Sichuang, China, in 2006 and 2012,

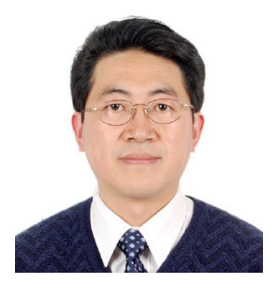

Minhao ZHU. He received his bachelor degree, master degree from Southwest Jiaotong University, Sichuang, China, in 1990 and 1993, respectively. Then he worked in Southwest Jiaotong University until now. From 1996 to 2001, he received his PhD degree
Chengdu University of Technology, Sichuang, China. In 2011, he was a PhD student in the Southwest Jiaotong University. His research interests include fretting wear and design of fastener connection.

respectively. He is currently a post-doctor at School of Mechanics and Engineering, Southwest Jiaotong University. His research interests include friction, wear and design of fastener connection.

of Engineering, University of Liverpool, UK. His main research areas are structural dynamics and control (particularly on friction-induced vibration and noise, and moving-load dynamics), and structural identification.

professor at School of Mechanical Engineering, Southwest Jiaotong University, deputy director of Tribology Research Institute. His research interests include friction and wear, surface engineering and instrument development.

respectively. After then, he worked in the same university and became an assistant researcher. His research interests include fretting fatigue and failure analysis.

from Southwest Jiaotong University, Sichuang, China. His current position is a Professor, Ph.D. student advisors, Cheung Kong Scholars and dean of School of Materials Science and Engineering. His research areas cover fretting wear, fretting fatigue, surface engineering and design of fastener connection. 